\title{
Difficulties and Countermeasures in the Development of Educational Economics and Management Discipline
}

\author{
Pang Zhaojun \\ Xi'an Fanyi University, Xi'an, Shaanxi, China, 710105
}

Keywords: education economy; management discipline; dilemma; countermeasure

\begin{abstract}
Education economy and management belong to the interdisciplinary subject of management, education and economics. The main feature is to apply the principles of economics and management to the practical education management. Although the development of the education economy and management discipline is to fully meet the needs of the actual development of modern society, however, it still faces many difficulties during the actual development, such as lack of research paradigm, misplaced curriculum system, lack of researchers and a single form of teaching and methods. This paper discusses the dilemma of the development of educational economics and management, and puts forward the rationalization countermeasures, such as reconstructing discipline research paradigm, constructing perfect curriculum system, training qualified research team and enriching teaching form and method.
\end{abstract}

\section{Introduction}

Education economy and management are interdisciplinary subjects that cover education, economics, and management. At present, the definition of its connotation in the academic community can be summarized as follows: Education economy and management is a reference to and use of the theoretical basis and research methods (multidisciplinary research methods) of pedagogy, management, and economics to study economic phenomena in education The cross-cutting disciplines of management issues, their interrelationships, and the laws of development and change. The task of educational economics and management is to explore the relationship between education and social development and politics and economy, analyze the operational mechanism of the education system with management theory, reform the management system of education, improve the allocation of education resources, and reveal education and economic management in modern development. The law of operation and changes in the development, scale, speed, and effectiveness of all types of education at all levels. Although the current development of the education economy and management discipline is in line with the current needs of our country's society, it still faces great challenges in order to further its development.

\section{Problems of Educational Economics and Management Discipline}

\subsection{Lack of research paradigm}

As far as educational economics and management disciplines are concerned, the lack of research paradigm is a sinking of discipline development. With the more esoteric research allowed by the paradigm, this is a sign that any scientific department has reached maturity. In general, there are four intrinsic signs that a discipline forms and gradually matures: First, there is a group of research teams that are pursuing and exploring in this subject area (problem domain). They have common goals, behavioral norms, and value standards. A relatively stable scientific community; Second, the establishment of research institutions, the organization of the Society, the establishment of academic conference systems, and the establishment of professional journals and other social institutions; Third, there has been a high level of research results, and gradually recognized by this scientific community as this The academic model of the discipline or the knowledge construction of the classic works; 
Fourth, there is an authoritative figure who has a degree of recognition in the academic world, and has become the founder or academic leader of this discipline. These are summarized as paradigms.

The lack of a research paradigm is attributed to the chaotic nature of education economics and management disciplines. This discipline is an interdisciplinary discipline that was formed by the adjustment and merger of two disciplines, educational economics and educational management, in 1997. However, it is difficult to determine the superior disciplines. Therefore, the construction of its own research paradigm has become an unavoidable primary issue in the construction of educational economics and management disciplines. The construction of this paradigm not only requires the scholars' self-discipline and self-discipline, but also needs to establish interdisciplinarity rather than multi-disciplinary awareness in the development of disciplines, and explore suitable methods for the organic integration of education, economy, and management.

\subsection{Misplacement of the curriculum system}

The curriculum system of educational economics and management is still unreasonable, mainly reflected in the misplacement of course content. This is inseparable from the affiliation of the discipline. For example, under the Department of Management, the education economics and management discipline is mainly focused on economic management courses, such as management, Western economics, strategic management, human resources management, etc., supplemented by two core courses as educational economics and education management. However, under the Department of Education, it focuses on education courses such as education economics, education management, education finance, educational research methods, education statistics, educational sociology, education policy research, etc., supplemented by human resources management and other management courses. This practice of linking course setting with affiliation is blind, and ignoring the discipline's own development laws is undesirable.

\subsection{Lack of researchers}

At present, 41 universities and colleges in China have established educational economics and management majors or disciplines. And have already achieved initial prosperity. However, it is not difficult to see from a few observations that there are still many problems exist in research teams in the education economics and management profession. The outstanding contradictions are, on the one hand, since the education economics and management professional education has been officially launched for less than a decade, the existing research teams are uneducated, uneducated, and economically conscious. On the other hand, most of the graduates with extremely limited education economics and management majors have not been able to invest in cross-disciplinary research on education economics and management, and the research team is still in short supply. Newly recruited researchers and teaching staff are often only can be transferred from other related disciplines and professions. This kind of temporary patchwork has influenced the continuous development of the discipline to a large extent.

\subsection{Single form \& method of teaching}

Teaching is a social practice of communication between teachers and students. The main function of subject teaching is to arouse students' cultural development by taking this activity as a source. The management of master's courses in education for universities in China is usually regulated by a unified syllabus. Most of the pilot universities use the teaching materials recommended by the Education Guidance Committee of the master's degree education. The compilation of the curriculum materials is under way, but the management of the curriculum is still lack of evaluation standards and supervision procedure. In this case, in addition to the influence of the traditional postgraduate education, although some of the teachers in the pilot universities have attached great importance to the system narration, as well as special lectures, classroom discussions and propositional assignments, and have made positive explorations in the case teaching, there are still quite a few trials in the case of the present situation. It is still a purely theoretical study to copy the teaching contents and teaching methods of the theoretical postgraduate education in the teaching of the related courses. The students take the courses and note taking as the main learning task. The teaching methods are not active, the 
teaching process is not standardized, and the guiding function of the teaching is not fully played.

\section{Countermeasures for the Development of Educational Economics and Management Discipline}

\subsection{Rebuild research paradigms}

The reconstructing of research paradigm for disciplines is a core topic for the future development of the subject of education economics and management. However, this construction will be a difficult exploration process. Firstly, discipline researchers need to establish good professional ethics, professional attitudes, and reexamine the complexity of theory and practice between education economics and management, gradually clarify the boundaries between each other, and explore the best fit of the three to build their own knowledge. The system lays a solid foundation. At the same time try to abandon traditional pedagogical concepts, adopt more multidisciplinary methods, go deep into philosophy, economics, management, sociology, culture, politics, and even related natural sciences that affect education processes and outcomes. In the academic field, a wide range of disciplines is used to perceive and interpret the internal mechanism of educational economy and management, and to find and explore the methods of discipline development through diverse research approaches. In addition, there is a need for the national education authority to further clarify the subject of education economics and management so as to provide the soil for its growth.

\subsection{Construct a complete curriculum system}

The construction of a comprehensive curriculum system includes two aspects, as shown in the following Table 1.

Table 1. Construction of a comprehensive curriculum system

\begin{tabular}{cl}
\hline No. & Items \\
\hline 1 & Constantly expanding the scope of the curriculum \\
2 & Course content should be closely linked to social life \\
\hline
\end{tabular}

At present, most of our education economy and management specialty belong to education, but the emphasis should not only be limited to the course of learning and education, but also the courses of economic management, such as management, western economics, strategic management, human resource management and so on. The curriculum should be both biased and balanced. Only by expanding the scope of the curriculum and widening the knowledge structure can the graduate students have a wide field of vision and facilitate the selection of research perspectives, otherwise it will directly affect the ability of scientific research.

Link theory with practice, so as to cultivate students' ability to solve practical problems by using the concept of knowledge. Organize and arrange related knowledge, experience, methods and means, and take the logical sequence of solving practical problems as the main line, which is very beneficial for us to promote the integration of knowledge, promote the updating of curriculum contents, and closely link teaching with social life.

\subsection{Develop a qualified research team}

Table 2. Develop qualified team

\begin{tabular}{cc}
\hline No. & \multicolumn{1}{c}{ Methods } \\
\hline 1 & Selecting excellent full-time teachers \\
2 & Hiring outstanding part-time teachers \\
3 & $\begin{array}{c}\text { Hire famous or accomplished experts and professors in relevant } \\
\text { disciplines }\end{array}$ \\
\hline
\end{tabular}

Education economics and management disciplines require unique research methods multidisciplinary research methods, which is, cross-discipline is an organic combination of multiple disciplines, and is naturally a method of integrating multiple disciplines in research methods. 
Multidisciplinary research methods are a great innovation in methodology and are also effective in practice. The research team of education economics and management specialty can be supplemented in the following three ways, as showed in table 2.

\subsection{Enrich teaching forms and methods}

Colleges and universities should advocate an open, constructive and creative form of teaching, with the emphasis on cultivating students' creative spirit and practical ability, and encouraging students to participate actively and explore actively and actively to acquire knowledge. It should not only renew educational concepts, innovating curriculum contents, but also emphasize creativity in teaching activities. Provide every member with good knowledge resources, so that each member can get more knowledge from them.

\section{Conclusion}

In view of the development of education economy and management specialty, this paper puts forward the countermeasures and suggestions to optimize the development of discipline: constructing a reasonable discipline, building a reasonable and high level teacher team, and improving the traditional teaching form, innovating the teaching methods, building a scientific and rational curriculum system. And improving the comprehensive quality of teachers and students in a comprehensive way, so that they can continue to innovate in the fierce social competition, which help to provide a constant source of motivation for the education development.

\section{References}

[1] Zhou Zhonggao, Justification of the discipline setting of educational economics andmanagement [J]. Education and Economics, 2003, (2): 5- 8.

[2] Guo Xin, Ren Zengyuan. Educational Economics and Management Subject: Predicament and Outlet [J]. Degree and Graduate Education, 2011, 04: 49-53.

[3] Wang Mei, Chen Shijun, Sun Wei. Difficulties and Countermeasures in the Development of Educational Economics and Management Subjects[J]. Journal of Southwest Jiaotong University, 2006, 02: 63-67.

[4] $\mathrm{Wu}$ Yongqiang. The difficulties and countermeasures of promoting the integration and development of interdisciplinary education in colleges and universities[J]. Brand, 2014, 10: 145+147. 